\title{
Comparative safety of inhaled medications in patients with chronic obstructive pulmonary disease: systematic review and mixed treatment comparison meta-analysis of randomised controlled trials
}

\author{
Yaa-Hui Dong, ${ }^{1}$ Hsien-Ho Lin, ${ }^{1}$ Wen-Yi Shau, ${ }^{2}$ Yun-Chun Wu, ${ }^{1}$ Chia-Hsuin Chang ${ }^{1,3}$ \\ Mei-Shu Lai ${ }^{1}$
}

- Additional materials are published online only. To view these files please visit the journal online (http://dx.doi. org/10.1136/thoraxjnl-2012201926).

${ }^{1}$ Graduate Institute of Epidemiology and Preventive Medicine, College of Public Health, National Taiwan University, Taipei, Taiwan ${ }^{2}$ Division of Health Technology Assessment, Center for Drug Evaluation, Taipei, Taiwan ${ }^{3}$ Department of Internal Medicine, National Taiwan University Hospital, Taipei, Taiwan

\section{Correspondence to} Dr Mei-Shu Lai, Graduate Institute of Epidemiology and Preventive Medicine, College of Public Health, National Taiwan University, 17, Xuzhou Road Taipei City 10055, Taiwan; mslai@ntu.edu.tw

Dr Chia-Hsuin Chang, Department of Internal Medicine, National Taiwan University Hospital, 7, Chung-Shan South Road, Taipei, 10002, Taiwan; chiahsuin123@yahoo.com.tw

Received 18 March 2012 Accepted 29 July 2012 Published Online First 6 October 2012

\begin{abstract}
Background The active-treatment comparative safety information for all inhaled medications in patients with chronic obstructive pulmonary disease (COPD) is limited. We aimed to compare the risk of overall and cardiovascular death for inhaled medications in patients with COPD.

Methods Through systematic database searching, we identified randomised controlled trials of tiotropium Soft Mist Inhaler, tiotropium HandiHaler, long-acting $\beta 2$ agonists (LABAs), inhaled corticosteroids (ICS), and LABAICS combination with at least a 6-month treatment duration. Direct comparison and mixed treatment comparison (MTC) meta-analyses were conducted to estimate the pooled ORs of death for each comparison. Results 42 trials with 52516 subjects were included. The MTC meta-analysis with the fixed effect model indicated tiotropium Soft Mist Inhaler was associated with an universally increased risk of overall death compared with placebo (OR 1.51; 95\% CI 1.06 to 2.19), tiotropium HandiHaler (OR 1.65; 95\% Cl 1.13 to 2.43), LABA (OR $1.63 ; 95 \% \mathrm{Cl} 1.10$ to 2.44$)$ and LABA-ICS (OR 1.90; $95 \% \mathrm{Cl} 1.28$ to 2.86). The risk was more evident for cardiovascular death, in patients with severe COPD, and at a higher daily dose. LABA-ICS was associated with the lowest risk of death among all treatments. No excess risk was noted for tiotropium HandiHaler or LABA. The results were similar for MTC and direct comparison metaanalyses, with less precision in the random effects model. Conclusion Our study provided a comparative safety spectrum for each category of inhaled medications. Tiotropium Soft Mist Inhaler had a higher risk of mortality and should be used with caution.
\end{abstract}

\section{INTRODUCTION}

Chronic obstructive pulmonary disease (COPD) is a substantial disease burden worldwide. ${ }^{1}{ }^{2}$ The Global Initiative for Chronic Obstructive Lung Disease guidelines recommend inhaled long-acting anticholinergics and $\beta 2$ agonists (LABAs) for maintenance therapy of COPD. ${ }^{2}$ Add-on treatment with inhaled corticosteroids (ICS) is indicated for patients with repeated exacerbations. ${ }^{2}$ However, an association of inhaled medications with cardiovascular complications has been noted, which is possibly related to their pharmacological effects. ${ }^{3}{ }^{4}$ Moreover, patients with COPD are susceptible to

\section{Key messages}

What is the key question?

- What is the difference in mortality for inhaled medications in patients with chronic obstructive pulmonary disease (COPD)?

What is the bottom line?

- Our mixed treatment comparison meta-analysis indicated that tiotropium Soft Mist Inhaler had a significant risk of overall death compared with placebo and other inhaled medications. The risk was more evident for cardiovascular death, in patients with severe COPD and at a higher daily dose. In contrast, a long-acting $\beta 2$ agonist (LABA)-inhaled corticosteroid (ICS) combination, tiotropium HandiHaler and LABAs had relatively safer profiles, and LABA-ICS seemed to have the lowest risk of overall death in patients with COPD.

\section{Why read on?}

- In view of the safety spectrum for each inhaled medication, our results provided substantial implications for healthcare professionals. The findings remind physicians that they should take patients' conditions into account, prescribe tiotropium Soft Mist Inhaler with more caution and consider alternative treatments in high risk populations.

overall and cardiovascular death. ${ }^{5}{ }^{6}$ Accordingly, it is important to examine the safety profiles of both outcomes for these medications.

Tiotropium, the only marketed long-acting anticholinergic, is approved as dry powder delivered via a HandiHaler device and solution delivered via a Respimat Soft Mist Inhaler (Boehringer Ingelheim, Ingelheim am Rhein, Germany). Based on the results of a large placebo-controlled trial, ${ }^{\mathrm{W} 1}$ (please note, references with the prefix ' $\mathrm{w}$ ' are listed in the online appendix), the US Food and Drug Administration (FDA) suggested that tiotropium HandiHaler has no excess risk of overall death and cardiovascular events. ${ }^{7-9}$ However, a non-significant increased risk of overall death for 
tiotropium Soft Mist Inhaler was noted in placebo-controlled trials, ${ }^{10 \mathrm{~W} 2} \mathrm{~W} 3$ and a nearly 50\% increased risk of overall death compared with placebo was reported in a meta-analysis. ${ }^{11}$ For LABAs, the US FDA has continually highlighted the increased risk of death in patients with asthma. ${ }^{12}{ }^{13}$ However, safety concerns about LABAs remain inconclusive in patients with COPD in several trials and meta-analyses. ${ }^{14}{ }^{15}$ W4-W7 For LABA-ICS, a marginally non-significant benefit for overall survival was found in a placebo-controlled trial ${ }^{\mathrm{W} 8}$ and a significantly decreased risk of death was observed in several meta-analyses. ${ }^{14} 16$

In view of the current evidence, it is necessary to address some limitations. First, none of the published trials simultaneously compared safety across various inhaled medications. Second, given the limited sample size, the risks of death for inhaled medications are generally undetermined by individual trials. Third, although traditional meta-analyses provide pooled risk estimates with better precision, the estimates are obtained only from direct comparison trials. Consequently, the information on comprehensive comparisons among different inhaled medications is insufficient.

The mixed treatment comparison (MTC) meta-analysis has a unique strength to integrate data from direct and indirect comparisons and facilitate multiple head-to-head comparisons across various treatments. ${ }^{17}$ To comprehensively compare the risk of mortality for inhaled medications in patients with COPD, we conducted both direct comparison and MTC meta-analyses of randomised controlled trials.

\section{METHODS}

\section{Data sources and searches}

We searched MEDLINE, CINAHL, Cochrane Library and ClinicalTrials.gov from inception to July 2011 (see the online appendix for the detailed search strategy). We examined the bibliographies of eligible trials and systematic review articles for relevant trials. To identify unpublished trials, we searched the manufacturers' clinical trials registers. ${ }^{18-20}$ If the outcomes of interest were not available from original articles or the above clinical trials registers, we contacted the authors or searched the US FDA website for additional information.

\section{Study selection}

The inclusion criteria were randomised, double-blind, active or placebo-controlled trials; patients with COPD of any severity; patients receiving predefined treatments, including tiotropium Soft Mist Inhaler, tiotropium HandiHaler, LABA, LABA-ICS and ICS; trials providing data about overall or cardiovascular death; and trials lasting for 6 months or more. We excluded trials if they included patients with asthma, involved nonpredefined treatment arms, and were published only in protocols, in abstracts, or in non-English languages.

\section{Outcome measures}

The primary outcome was overall death. The secondary outcome was cardiovascular death based on the preferred terms defined by the Medical Dictionary for Regulatory Activities (see the online appendix). ${ }^{21}$

\section{Data extraction and assessment of risk of bias}

Two investigators (YHD (pharmacist) and CHC (physician)) independently evaluated each identified reference and retrieved relevant characteristics from eligible trials. To assess the risk of bias of individual trials, we applied Cochrane's risk of bias tool. We also recorded how adverse events were monitored. ${ }^{22}$ Any disagreement was resolved by discussion and consensus (see the online appendix).

\section{Statistical analysis}

We used the intention-to-treat analysis. A two-sided $\alpha$ value of 0.05 was defined for statistical significance. The Peto method was applied for the direct comparison meta-analysis of rare events. $^{23}$ The Mantel-Haenszel method with the fixed effect model and different continuity correction factors was performed for the sensitivity analysis. ${ }^{24}$ For each pairwise comparison, we estimated the risks of overall and cardiovascular death with the pooled OR and 95\% CI. Statistical heterogeneity was evaluated by the $\mathrm{I}^{2}$ statistic, with a value of $50 \%$ or more illustrating a substantial level of heterogeneity. Publication bias was assessed by the funnel plot, the Begg's test and the Egger's test (see the online appendix). ${ }^{22}$

The Bayesian Markov chain Monte Carlo methods with fixed and random effects models were used for the MTC meta-analysis (see the online appendix). ${ }^{17}$ Results were presented as the OR and 95\% credible interval (CrI). For each treatment, we also estimated the probability of overall and cardiovascular death and the probability of being ranked as the riskiest intervention.

We performed subgroup analyses to address the risks of inhaled medications in trials with longer treatment durations (study duration $\geq 1$ year) and trials enrolling patients with severe COPD (forced expiratory volume in $1 \mathrm{~s}\left(\mathrm{FEV}_{1}\right)<50 \%$ of predicted value). ${ }^{2}$ A potential dose-response relation of tiotropium Soft Mist Inhaler was examined by stratification analyses by individually comparing $5 \mu \mathrm{g} / \mathrm{day}$ and $10 \mu \mathrm{g} / \mathrm{day}$ of tiotropium Soft Mist Inhaler with other treatments.

To address the possible trial heterogeneities and misclassification of cardiovascular death, we performed additional analyses. Meta-regression was conducted to adjust for related demographic characteristics (see the online appendix). Sensitivity analyses were performed by excluding trials with the ICS withdrawal design and by restricting the analyses to trials with objective adjudication of cause of death. ${ }^{25}$

STATA V.9.0 (StataCorp) and WinBUGS V.1.4.3 (MRC Biostatistics Unit, Cambridge, UK) was used for direct comparison and MTC meta-analyses, respectively. The WinBUGS code is shown in the online appendix. The predefined protocol is available from the authors on request.

\section{RESULTS}

\section{Eligible trials}

A total of 42 eligible trials reporting on overall death ${ }^{\mathrm{W} 1-\mathrm{W} 44}$ and 31 trials reporting on cardiovascular death ${ }^{\mathrm{W} 1-\mathrm{W} 3}$ W5 $\mathrm{W} 6$ W8-W12 W15 W17-W23 W25 W27-W44 were included in the meta-analysis (online appendix and figure 1).

These 42 trials enrolled 52516 subjects, with similar characteristics across trials with different treatments (64 years of age, $73 \%$ men, $37 \%$ current smokers, 1 year study duration, and $44 \%$ of predicted value in $\left.\mathrm{FEV}_{1}\right)$. However, more subjects combined LABA or ICS use at baseline in tiotropium Soft Mist Inhaler and HandiHaler trials (table 1 and online tables S1 and S2).

\section{Assessment of risk of bias of included studies}

All 42 trials were randomised, double-blind, with 24 trials addressing adequate randomisation procedures. Forty-one trials stated the withdrawal rate, which varied across trials and treatment groups (with the lowest value of $17 \%$ in the tiotropium Soft Mist Inhaler group and the highest values of $33 \%$ in the ICS and placebo groups). Twenty-eight trials described the 
Figure 1 Flow diagram of the search process. *The number of references identified through each database was 731 (MEDLINE), 9 (CINAHL), 1464 (Cochrane) and 40 (ClinicalTrials.gov). tReferences were identified through bibliographies of eligible trials and systematic review articles and the clinical study registers of pharmaceutical companies. $\ddagger$ References were usually excluded for more than one reason. ICS, inhaled corticosteroid; LABA, long-acting $\beta 2$ agonist; $\mathrm{TIO}-\mathrm{HH}$, tiotropium dry powder delivered via HandiHaler; TIO-SMI, tiotropium solution delivered via Resipmat Soft Mist Inhaler.

\section{References identified throug database searching*}

3 References identified through database $\dagger$

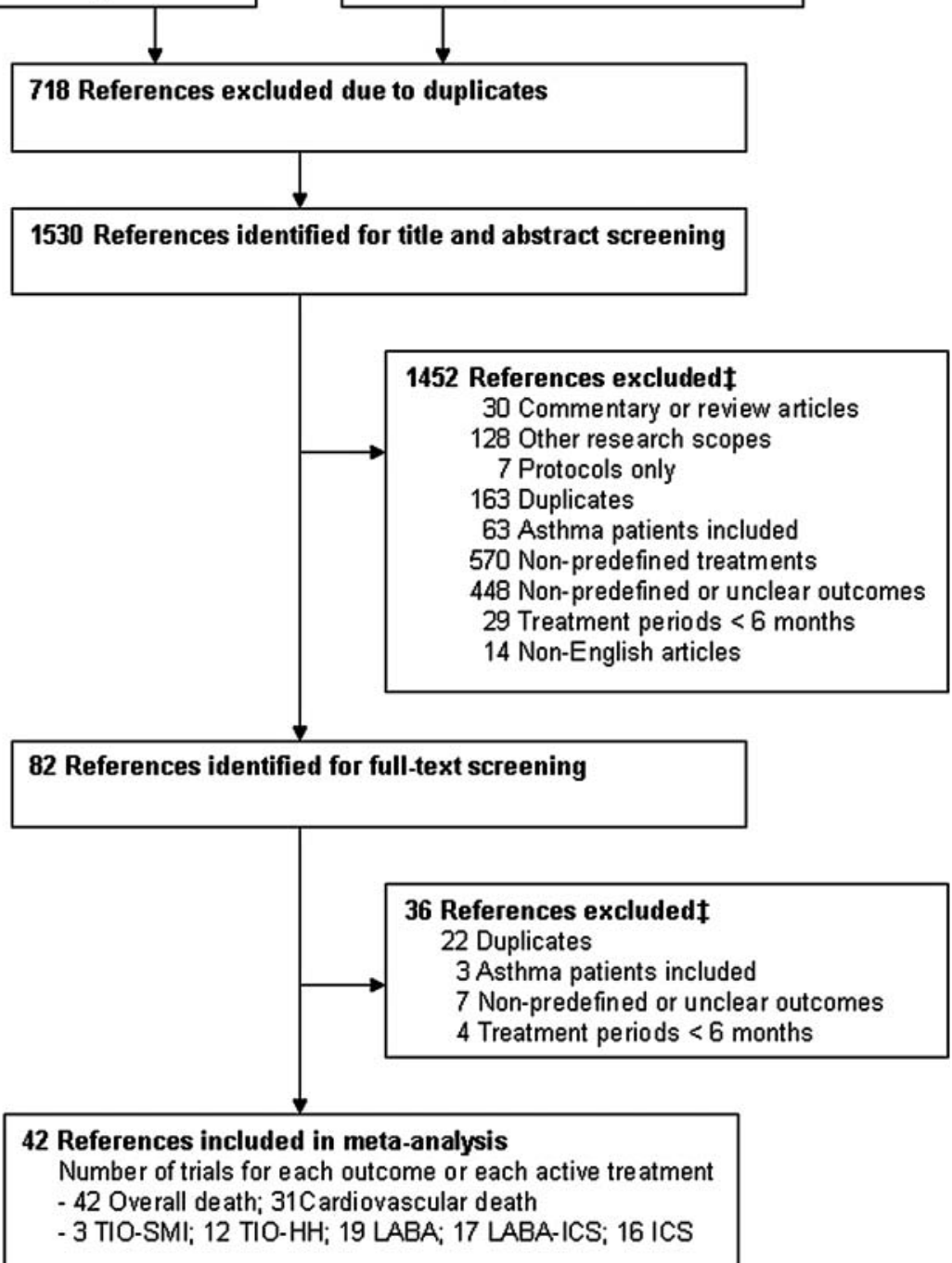

Table 1 Summary of trial characteristics and patient characteristics at baseline. Figures are means (ranges)

\begin{tabular}{|c|c|c|c|c|c|c|c|c|c|}
\hline & Age (years) & Men (\%) & $\begin{array}{l}\text { Current } \\
\text { smokers (\%) }\end{array}$ & $\begin{array}{l}\text { Study } \\
\text { duration } \\
\text { (years) }\end{array}$ & $\begin{array}{l}\mathrm{FEV}_{1}(\% \text { of } \\
\text { predicted } \\
\text { value) }\end{array}$ & $\begin{array}{l}\text { Subjects with } \\
\text { concomitant use } \\
\text { of LABA }(\%)\end{array}$ & $\begin{array}{l}\text { Subjects with } \\
\text { concomitant } \\
\text { use of ICS (\%) }\end{array}$ & $\begin{array}{l}\text { Withdrawal } \\
\text { rate }(\%)\end{array}$ & $\begin{array}{l}\text { Lost to } \\
\text { follow-up (\%) }\end{array}$ \\
\hline $\begin{array}{l}\text { Total } \\
(\mathrm{N}=42)\end{array}$ & $64.0(52.4-67.9)$ & $73.2(4.5-98.5)$ & $37.1(21.7-100)$ & $1.2(0.5-4)$ & $44.4(34.4-86.6)$ & $33.3(3.0-60.1)$ & $47.3(14.0-83.2)$ & $27.9(0.8-59.0)$ & $1.5(0.0-8.6)$ \\
\hline \multicolumn{10}{|c|}{ Stratified by treatment* } \\
\hline $\begin{array}{l}\text { TIO-SMI } \\
(n=3)\end{array}$ & $64.9(64.8-65.0)$ & $76.4(74.2-77.5)$ & $36.0(35.8-36.3)$ & $1(-)$ & $45.5(45.3-46.0)$ & $41.5(29.7-53.4)$ & $54.9(53.7-56.1)$ & $17.1(16.0-20.4)$ & $1.3(1.1-1.7)$ \\
\hline $\begin{array}{l}\text { TIO-HH } \\
(n=12)\end{array}$ & $64.4(62.9-67.9)$ & $77.0(56.5-98.5)$ & $33.2(24.1-58.4)$ & $1.2(0.5-4)$ & $45.3(34.4-50.0)$ & $42.5(17.5-53.8)$ & $59.1(42.4-75.3)$ & $24.3(14.7-42.0)$ & $1.1(0.2-2.1)$ \\
\hline $\begin{array}{l}\text { LABA } \\
(n=19)\end{array}$ & $63.7(60.0-65.7)$ & $72.0(54.0-80.6)$ & $39.3(34.5-55.0)$ & $1(0.5-3)$ & $43.9(36.0-53.8)$ & $27.0(3.0-54.5)$ & $37.3(14.0-57.0)$ & $25.2(10.0-43.5)$ & $1.1(0.4-3.0)$ \\
\hline $\begin{array}{l}\text { LABA-ICS } \\
(n=17)\end{array}$ & $64.3(63.2-66.2)$ & $72.2(54.0-89.2)$ & $36.5(21.7-50.8)$ & $1.2(0.5-3)$ & $40.5(36.0-47.8)$ & $26.8(3.0-54.5)$ & $34.6(14.0-54.3)$ & $26.8(12.2-39.0)$ & $1.8(0.0-2.5)$ \\
\hline $\begin{array}{l}\text { ICS } \\
(n=16)\end{array}$ & $63.3(52.4-67.4)$ & $69.5(4.5-84.5)$ & $45.8(27.5-100)$ & $1.5(0.5-4)$ & $44.0(36.0-86.6)$ & $29.1(8.5-56.0)$ & $44.0(19.8-83.2)$ & $33.5(0.8-43.8)$ & $2.0(0.0-8.6)$ \\
\hline$P L(n=34)$ & $64.1(52.4-67.9)$ & $73.2(4.5-98.5)$ & $34.9(21.7-100)$ & $1.2(0.5-4)$ & $44.1(34.4-86.6)$ & $34.2(8.5-60.1)$ & $52.3(19.8-83.2)$ & $33.3(0.8-59.0)$ & $2.0(0.0-6.8)$ \\
\hline
\end{tabular}


fraction of lost to follow-up, which was relatively low and less variant across different treatment groups (table 1 and online tables S2 and S3). Practice of adverse event monitoring was heterogeneous across trials, with six trials (25 533 subjects) describing objective adjudication of cause of death (online table S3).

\section{Direct comparison meta-analysis}

Figure 2 displays the network of each pairwise comparison. Statistical heterogeneity was minimal, with the exception of tiotropium HandiHaler versus LABA for overall death $\left(\mathrm{I}^{2}=59.4 \%\right)$.

The results of the direct comparison meta-analysis are summarised in table 2. For overall death and in comparison with placebo, tiotropium Soft Mist Inhaler was associated with a significantly increased risk (OR 1.49; 95\% CI 1.05 to 2.11) whereas LABA-ICS showed a survival benefit (OR 0.81; 95\% CI 0.67 to 0.98 ). Tiotropium HandiHaler, LABA and ICS had no excess risks. Among the active treatment comparisons, tiotropium HandiHaler posed a significantly higher risk than LABA-ICS (OR 1.81; 95\% CI 1.07 to 3.05 ) based on one trial result while LABA-ICS showed a significantly decreased risk over ICS (OR $0.78 ; 95 \%$ CI 0.64 to 0.94 ). For cardiovascular death and in comparison with placebo, tiotropium Soft Mist Inhaler displayed a more pronounced risk (OR 1.96; 95\% CI 1.07 to 3.60 ) while LABA was associated with a significantly decreased risk (OR 0.67; 95\% CI 0.48 to 0.95 ). No significant difference was observed among other comparisons. The results of the Peto method were similar to those of the Mantel-Haenszel method (online table S4). Publication bias was not detected by the funnel plot, the Begg's test or the Egger's test (online figure S1).

\section{MTC meta-analysis}

The results of the MTC meta-analysis are listed in table 2. For overall death and in the fixed effect model, patients using tiotropium Soft Mist Inhaler had universally increased risks compared with those receiving placebo (OR $1.51 ; 95 \% \operatorname{CrI} 1.06$ to 2.19 ) or those using tiotropium HandiHaler (OR 1.65; 95\% CrI 1.13 to 2.43), LABA (OR 1.63; 95\% CrI 1.10 to 2.44 ) and LABA-ICS (OR 1.90; 95\% CrI 1.28 to 2.86). In contrast, LABA-ICS demonstrated a beneficial profile versus placebo (OR $0.80 ; 95 \%$ CrI 0.67 to 0.94 ) or ICS (OR $0.77 ; 95 \%$ CrI 0.64 to 0.93$)$. For cardiovascular death, tiotropium Soft Mist Inhaler had a more apparent risk compared with placebo (OR 2.07; 95\% CrI 1.09 to 4.16), tiotropium HandiHaler (OR 2.38; 95\% CrI 1.20 to 4.99 ), LABA (OR 3.04 ; 95\% CrI 1.48 to 6.55 ), LABA-ICS (OR 2.79; 95\% CrI 1.37 to 6.02) and ICS (OR 2.39; 95\% CrI 1.18 to 5.12). In contrast, LABA had a decreased risk versus placebo (OR $0.68 ; 95 \%$ CrI 0.50 to 0.93 ). In the random effects model, tiotropium Soft Mist Inhaler consistently demonstrated an increased risk of overall death versus any
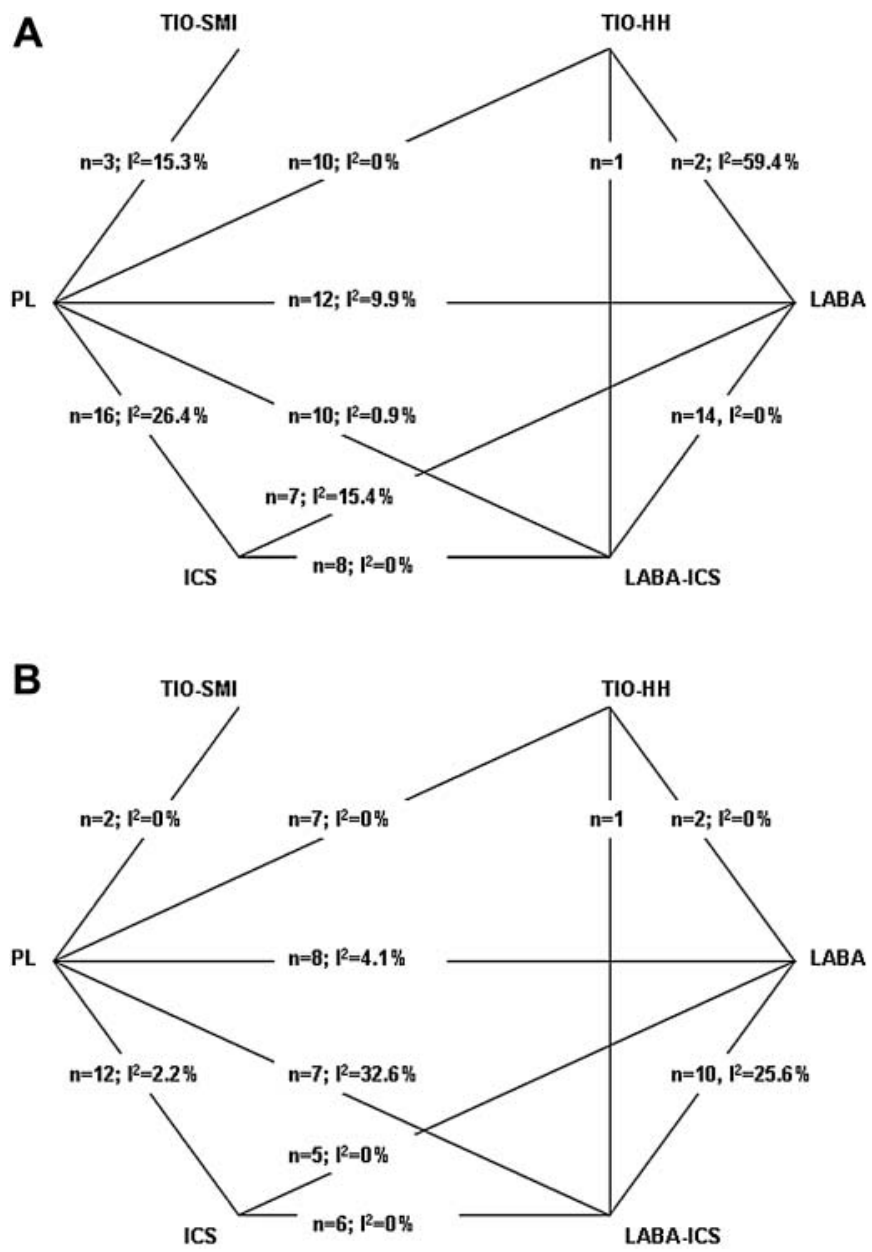

Figure 2 Network of comparisons included in meta-analysis. A. Overall death: $\mathrm{N}=42$. B. Cardiovascular death: $\mathrm{N}=31$. The denotation of ' $\mathrm{N}$ ' and ' $n$ ' represented number of trials reporting on each outcome and with each direct pairwise comparison, respectively. Statistical heterogeneity was represented as the $\mathrm{I}^{2}$ value. ICS, inhaled corticosteroid; LABA, long-acting $\beta 2$ agonist; PL, placebo; TIO-HH, tiotropium dry powder delivered via HandiHaler; TIO-SMI, TIO-HH, tiotropium dry powder delivered via HandiHaler. 
Table 2 Risk of overall death and cardiovascular death for each pairwise comparison from the direct comparison and MTC meta-analyses

\begin{tabular}{|c|c|c|c|c|c|c|}
\hline \multirow[b]{2}{*}{ Comparison } & \multicolumn{3}{|l|}{ Overall death $(\mathrm{N}=42)$} & \multicolumn{3}{|c|}{ Cardiovascular death $(\mathrm{N}=31)$} \\
\hline & $\begin{array}{l}\text { Direct comparison Peto } \\
\text { OR }(95 \% \mathrm{Cl})\end{array}$ & $\begin{array}{l}\text { MTC fixed effect } \\
\text { OR }(95 \% \mathrm{Crl})\end{array}$ & $\begin{array}{l}\text { MTC random effects } \\
\text { OR }(95 \% \mathrm{Crl})\end{array}$ & $\begin{array}{l}\text { Direct comparison Peto } \\
\text { OR }(95 \% \mathrm{Cl})\end{array}$ & $\begin{array}{l}\text { MTC fixed effect } \\
\text { OR ( } 95 \% \mathrm{Crl})\end{array}$ & $\begin{array}{l}\text { MTC random effects } \\
\text { OR ( } 95 \% \mathrm{Crl})\end{array}$ \\
\hline \multicolumn{7}{|l|}{ TIO-SMI vs } \\
\hline $\mathrm{TIO}-\mathrm{HH}$ & - & 1.65 (1.13 to 2.43$)$ & 1.66 (1.04 to 2.75$)$ & - & 2.38 (1.20 to 4.99$)$ & 2.18 (0.73 to 6.48$)$ \\
\hline LABA & - & 1.63 (1.10 to 2.44$)$ & 1.61 (1.002 to 2.66$)$ & - & 3.04 (1.48 to 6.55$)$ & 2.80 (0.91 to 8.52 ) \\
\hline LABA-ICS & - & 1.90 (1.28 to 2.86$)$ & 1.93 (1.20 to 3.24$)$ & - & 2.79 (1.37 to 6.02$)$ & 3.00 (1.08 to 9.95$)$ \\
\hline ICS & - & $1.47(0.99$ to 2.21$)$ & $1.55(0.96$ to 2.65$)$ & - & 2.39 (1.18 to 5.12$)$ & 2.31 (0.76 to 7.15$)$ \\
\hline PL & 1.49 (1.05 to 2.11$)$ & 1.51 (1.06 to 2.19$)$ & $1.54(1.01$ to 2.43$)$ & $1.96(1.07$ to 3.60$)$ & 2.07 (1.09 to 4.16$)$ & $2.18(0.91$ to 6.19$)$ \\
\hline \multicolumn{7}{|l|}{ TIO-HH vs } \\
\hline \multirow[t]{2}{*}{ LABA } & $0.76(0.55$ to 1.06$)$ & $0.99(0.83$ to 1.19$)$ & $0.97(0.74$ to 1.26$)$ & 1.24 (0.49 to 3.12$)$ & $1.27(0.88$ to 1.87$)$ & 1.29 (0.67 to 2.41$)$ \\
\hline & 1.81 (1.07 to 3.05$)$ & $1.16(0.95$ to 1.41$)$ & $1.16(0.88$ to 1.55$)$ & 2.05 (0.97 to 4.34$)$ & $1.17(0.81$ to 1.69$)$ & 1.37 (0.77 to 2.92$)$ \\
\hline \multicolumn{7}{|l|}{ LABA-ICS* } \\
\hline ICS & - & $0.89(0.73$ to 1.09$)$ & $0.93(0.71$ to 1.31$)$ & - & $1.00(0.69$ to 1.46$)$ & $1.06(0.52$ to 2.20$)$ \\
\hline PL & $0.93(0.81$ to 1.07$)$ & $0.92(0.81$ to 1.05$)$ & $0.93(0.75$ to 1.17$)$ & $0.81(0.61$ to 1.06$)$ & $0.87(0.67$ to 1.13$)$ & $1.00(0.64$ to 1.89$)$ \\
\hline \multicolumn{7}{|l|}{ LABA vs } \\
\hline LABA-ICS & 1.10 (0.91 to 1.32$)$ & 1.17 (0.98 to 1.39$)$ & 1.20 (0.95 to 1.54$)$ & 0.84 (0.59 to 1.20$)$ & $0.92(0.65$ to 1.29$)$ & 1.07 (0.64 to 2.16$)$ \\
\hline ICS & 0.86 (0.71 to 1.04$)$ & 0.90 (0.76 to 1.07 ) & 0.95 (0.75 to 1.32 ) & 0.73 (0.50 to 1.07$)$ & 0.79 (0.56 to 1.11$)$ & 0.82 (0.44 to 1.64$)$ \\
\hline $\mathrm{PL}$ & 0.90 (0.75 to 1.08$)$ & 0.93 (0.79 to 1.09 ) & 0.95 (0.77 to 1.23 ) & 0.67 (0.48 to 0.95$)$ & 0.68 (0.50 to 0.93$)$ & 0.78 (0.48 to 1.55$)$ \\
\hline \multicolumn{7}{|l|}{ LABA-ICS vs } \\
\hline ICS & 0.78 (0.64 to 0.94$)$ & $0.77(0.64$ to 0.93$)$ & $0.80(0.62$ to 1.03$)$ & 0.97 (0.68 to 1.39$)$ & $0.85(0.61$ to 1.20$)$ & 0.77 (0.36 to 1.38$)$ \\
\hline PL & 0.81 (0.67 to 0.98$)$ & 0.80 (0.67 to 0.94$)$ & $0.80(0.67$ to 1.09$)$ & 0.81 (0.58 to 1.14$)$ & 0.74 (0.54 to 1.01$)$ & $0.73(0.41$ to 1.30$)$ \\
\hline \multicolumn{7}{|l|}{ ICS vs } \\
\hline PL & 1.01 (0.86 to 1.20$)$ & 1.03 (0.88 to 1.21$)$ & $1.00(0.76$ to 1.23$)$ & 0.88 (0.64 to 1.20$)$ & 0.87 (0.64 to 1.17$)$ & 0.94 (0.57 to 1.85$)$ \\
\hline
\end{tabular}

comparators, and showed an increased risk of cardiovascular death versus LABA-ICS. Between direct comparison and MTC meta-analyses, the direction in OR was identical for each comparison. The difference in OR was also minimal (within 10\%), with the exception of tiotropium HandiHaler versus LABA or LABA-ICS (over 30\%).

Among all the treatments, tiotropium Soft Mist Inhaler had the highest probability of overall and cardiovascular death $(8 \%$ and $3.5 \%$, respectively), with an approximate probability of $95 \%$ of being ranked as the riskiest treatment. In contrast, LABA-ICS had the lowest probability of overall death $(4.5 \%)$, with a probability of $0 \%$ of being ranked as the riskiest treatment (table 3).

The analyses restricted to trials with longer treatment duration and trials enrolling patients with severe COPD showed similar results to the main analysis, although the risk of cardiovascular death associated with tiotropium Soft Mist Inhaler was slightly higher for patients with severe COPD using the fixed effect model (table 4). Three tiotropium Soft Mist Inhaler trials included a group treated with $5 \mu \mathrm{g} /$ day and two included a group treated with $10 \mu \mathrm{g} /$ day. Use of $10 \mu \mathrm{g} /$ day tiotropium Soft Mist Inhaler tended to be associated with a higher risk of overall death against all comparators, although the risks of cardiovascular death were irrespective of the dose of tiotropium (figure 3).

The MTC meta-regression adjusting for demographic characteristics did not substantially change the increased risk for tiotropium Soft Mist Inhaler versus other treatments (online tables S5 and S6). The sensitivity analyses which excluded trials with the ICS withdrawal design and restricted trials with objective adjudication of cause of death yielded similar results to the main analysis (online tables S7 and S8).

\section{DISCUSSION}

This study demonstrated that tiotropium Soft Mist Inhaler was associated with higher risks of overall and cardiovascular death compared with placebo and other inhaled medications, with a potential dose-response effect on overall death. The risk of cardiovascular death associated with tiotropium Soft Mist Inhaler was also higher for patients with severe COPD, although this may simply be because more severe comorbidities impair cardiovascular systems. Instead, LABA-ICS was associated with the lowest risk of overall death. No excess risk was noted for tiotropium HandiHaler or LABA. In contrast with the Global Initiative for Chronic Obstructive Lung Disease guidelines recommending tiotropium or LABA as first-line maintenance therapy, our study highlighted the potential harm of tiotropium Soft Mist Inhaler. This finding should be weighed against other risks and benefits for individual treatments and allows a revision of the recommendations for management of COPD.

\section{Strengths of this study}

This study compared different formulations of tiotropium and different categories of inhaled medications. Given that inhaled pharmacological treatment is the cornerstone of management of COPD, the question for physicians is not whether one drug should be prescribed but rather which one to choose. Our approach accordingly addressed the practical challenge and provided information for making treatment decisions. In addition, compared with previous meta-analyses, ${ }^{14-16} \quad 21 \quad 26-28$ W45 we included more trials, including a large comparative trial of inhaled long-acting bronchodilators. ${ }^{20}$ This amplified the sample size of the study and enabled us to make more precise 
Table 3 Probability of overall death and cardiovascular death and probability of being ranked as the riskiest intervention for each treatment from the MTC meta-analysis

\begin{tabular}{|c|c|c|c|c|c|c|c|c|}
\hline \multirow[b]{3}{*}{ Treatment } & \multicolumn{4}{|l|}{ Overall death $(\mathrm{N}=42)$} & \multicolumn{4}{|c|}{ Cardiovascular death $(\mathrm{N}=31)$} \\
\hline & \multicolumn{2}{|c|}{ Probability of death, $\%(95 \% \mathrm{Crl})$} & \multicolumn{2}{|c|}{$\begin{array}{l}\text { Probability of being } \\
\text { ranked as the riskiest } \\
\text { intervention, } \%\end{array}$} & \multicolumn{2}{|c|}{ Probability of death, $\%$ (95\% Crl) } & \multicolumn{2}{|c|}{$\begin{array}{l}\text { Probability of being } \\
\text { ranked as the riskiest } \\
\text { intervention, } \%\end{array}$} \\
\hline & Fixed effect & Random effects & $\begin{array}{l}\text { Fixed } \\
\text { effect }\end{array}$ & $\begin{array}{l}\text { Random } \\
\text { effects }\end{array}$ & Fixed effect & Random effects & $\begin{array}{l}\text { Fixed } \\
\text { effect }\end{array}$ & $\begin{array}{l}\text { Random } \\
\text { effects }\end{array}$ \\
\hline TIO-SMI & $8.26(2.55$ to 23.61$)$ & 8.32 (2.51 to 24.46$)$ & 96.94 & 94.61 & $3.63(0.98$ to 12.82$)$ & $3.83(0.90$ to 15.63$)$ & 98.34 & 89.49 \\
\hline TIO-HH & $5.19(1.64$ to 15.16$)$ & $5.18(1.62$ to 15.40$)$ & 0.08 & 0.79 & 1.56 (0.47 to 4.98$)$ & $1.79(0.51$ to 6.29$)$ & 0.27 & 4.74 \\
\hline LABA & $5.26(1.65$ to 15.38$)$ & 5.34 (1.65 to 16.03$)$ & 0.15 & 1.30 & $1.22(0.37$ to 4.00$)$ & $1.40(0.39$ to 5.07$)$ & 0.01 & 1.04 \\
\hline LABA-ICS & $4.52(1.41$ to 13.45$)$ & 4.50 (1.39 to 13.56$)$ & 0.00 & 0.06 & 1.33 (0.40 to 4.32$)$ & $1.29(0.35$ to 4.48$)$ & 0.04 & 0.31 \\
\hline ICS & $5.78(1.82$ to 16.73$)$ & $5.52(1.72$ to 16.33$)$ & 2.50 & 2.57 & $1.55(0.47$ to 5.05$)$ & $1.70(0.47$ to 6.03$)$ & 0.45 & 3.60 \\
\hline PL & $5.62(1.79$ to 16.23$)$ & 5.57 (1.77 to 16.26$)$ & 0.33 & 0.67 & $1.78(0.56$ to 5.56$)$ & $1.77(0.55$ to 5.49$)$ & 0.91 & 0.82 \\
\hline
\end{tabular}

estimates. Furthermore, our subgroup and stratification analyses facilitated special populations or scenarios to be identified that require more caution when using tiotropium Soft Mist Inhaler.

\section{Safety of tiotropium Soft Mist Inhaler}

A recent meta-analysis reported that tiotropium Soft Mist Inhaler had an increased risk of overall death (risk ratio 1.52; $95 \%$ CI 1.06 to 2.16 ) and cardiovascular death (risk ratio 2.05; $95 \%$ CI 1.06 to 3.99 ) versus placebo. ${ }^{11}$ Our study further highlighted safety concerns of tiotropium Soft Mist Inhaler versus other active treatments. Some possible mechanisms have been proposed. One is that use of tiotropium Soft Mist Inhaler could yield higher systematic drug exposure compared with tiotropium HandiHaler, ${ }^{29}$ although this was not observed in Japanese research. ${ }^{30}$ Evidence also suggested that patients receiving a higher dose of tiotropium Soft Mist Inhaler had higher peak concentrations. $^{29}$ Another mechanism is the potential effect of underlying rhythm disorders on mortality. Data suggested that the elevated risks of tiotropium Soft Mist Inhaler compared with placebo were up to 3.2-fold for overall death and 8.6-fold for cardiovascular death in patients with cardiac rhythm disorders. ${ }^{7}$ However, this substantial risk was not detected in patients without cardiac dysrhythmias. ${ }^{7} 8$ Further studies, such as well designed randomised controlled trials with a head-to-head comparison of different formulations and doses of tiotropium ${ }^{31}$ are warranted to clarify these hypotheses.

\section{Safety of tiotropium HandiHaler, LABA and LABA-ICS}

Despite the potential harm of LABA among patients with asthma, we found no excess risk of LABA in patients with COPD. LABA tended to have a non-significant increased risk compared with LABA-ICS; however, the estimate was imprecise, with a likely inflated type I error due to multiple statistical tests. Meanwhile, we observed that tiotropium HandiHaler posed a nearly $80 \%$ increased risk of overall death when directly compared with LABA-ICS, although the result was based on one trial and became non-significant in the MTC analysis. A large population-based cohort study reported that tiotropium HandiHaler was associated with an excess risk of overall death versus LABA (HR 1.14; 95\% CI 1.09 to 1.19 ). ${ }^{32}$ However, it was noted that more patients in the LABA group combined ICS use during the study period. Considering all the evidence,
LABA-ICS may be associated with the lowest risk profile. Further studies are needed to identify optimal therapeutic combinations and regimes for treating patients with COPD.

\section{Limitations}

Our study has limitations. First, the validity of our MTC meta-analysis relies on the assumptions of similarity of demographic characteristics across trials and homogeneity of each relative treatment effect. ${ }^{33}$ In our study, despite some variation, demographic characteristics were generally similar and the $\mathrm{I}^{2}$ statistic was minimal. To manage possible trial heterogeneities in the MTC meta-analysis, we used the random effects model and the meta-regression and yielded similar findings. Risk estimates were also consistent between direct comparison and MTC meta-analyses in terms of directions and magnitudes. All these approaches enhanced the validity of our study. However, we cannot rule out the influences from unmeasured covariates. Given rare events and few trials for some comparisons, statistical heterogeneity or publication bias is likely underpowered. We should also note that the difference in OR between direct comparison and MTC meta-analyses was particularly apparent in the comparisons of tiotropium HandiHaler versus LABA or LABA-ICS, which may be associated with the small number of trials involved in these comparisons. ${ }^{34}$ Second, several trials were prevalent-user designs ${ }^{\mathrm{W} 8} \mathrm{~W} 20$ or designed for investigating ICS withdrawal effects rather than treatment effects. Notably, a high percentage of subjects combined LABA or ICS use in tiotropium trials. Our sensitivity analysis and meta-regression adjustment for percentage of concomitant use of LABA or ICS did not change the main findings. However, further studies are necessary to clarify the standalone or add-on effects of these drugs taking into account these complicated elements. Third, all included trials excluded patients with significant diseases and half of them excluded patients with specific cardiovascular morbidities. This may limit the generalisability of our findings to frailer populations in real practice. Fourth, few tiotropium Soft Mist Inhaler trials were involved in our study and precluded further exploration, such as the dose-response effect. Fifth, cardiovascular death was a sparse, non-predefined outcome and without a homogeneous definition across trials. This may result in imprecise estimates and outcome misclassification is possible. However, we constructed this composite endpoint according to 
Table 4 Subgroup analysis for risk of overall death and cardiovascular death for each pairwise comparison from the MTC meta-analysis

Overall death $(\mathrm{N}=42$ )

Study duration $\geq 1$ year $(\mathrm{N}=27)$ (95\% Crl)

$\mathrm{FEV}_{1}<50 \%$ predicted value $(\mathrm{N}=30)$

Fixed effect $O R \quad$ Random effects $O R$
(95\% Crl) (95\% Crl)

\section{Study duration $\geq 1$ year $(\mathrm{N}=18)$}

Comparison

TIO-SMI vs

TIO-HH $\quad 1.65$ (1.12 to 2.43$)$

LABA $\quad 1.66(1.11$ to 2.48$)$

LABA-ICS $\quad 1.94$ (1.30 to 2.92)

ICS $\quad 1.49(0.999$ to 2.22$)$

PL $\quad 1.52(1.06$ to 2.19$)$

TIO-HH vs

LBA

LABA $\quad 1.01(0.84$ to 1.21$)$

LABA-ICS $\quad 1.18(0.97$ to 1.44$)$

ICS $\quad 0.90(0.74$ to 1.10$)$

PL $\quad 0.92(0.81$ to 1.05$)$

LABA vs

LABA-ICS $\quad 1.17$ (0.98 to 1.40$)$

ICS $\quad 0.90(0.75$ to 1.07$)$

PL $\quad 0.92(0.78$ to 1.07$)$

LABA-ICS vs

ICS 0.77 (0.64 to 0.92$)-0.79(0.60$ to 1.10$)$

ICS $\quad 0.77(0.64$ to 0.92$) \quad 0.79(0.60$ to 1.10$)$

PL $\quad 0.78(0.66$ to 0.93$) \quad 0.77$ (0.59 to 1.01$)$

1.65 (0.999 to 2.78$)$

1.66 (1.01 to 2.80$)$

2.02 (1.22 to 3.47$)$

1.64 (1.13 to 2.43$)$

1.63 (1.10 to 2.45$)$

1.90 (1.28 to 2.87$)$

1.67 (1.03 to 2.89$)$

1.65 (1.004 to 2.88$)$

1.98 (1.20 to 3.50$)$

$(0.99$ to 2.79$)$

$1.45(0.97$ to 2.20$)$

1.57 (0.96 to 3.10$)$

1.51 (1.06 to 2.20$) \quad 1.55$ (1.01 to 2.52 )

0.99 (0.83 to 1.19$) \quad 0.99(0.74$ to 1.33$)$

$1.16(0.95$ to 1.42$) \quad 1.18(0.87$ to 1.64$)$

$0.89(0.72$ to 1.09$) \quad 0.94(0.68$ to 1.50$)$

0.92 (0.81 to 1.05$)$

0.93 (0.73 to1.19)

$1.16(0.98$ to 1.39$)$

0.89 (0.74 to 1.07$)$

1.19 (0.92 to 1.58$)$

0.95 (0.72 to 1.44$)$

0.94 (0.72 to 1.22$)$

$0.76(0.63$ to 0.92$) \quad 0.79(0.60$ to 1.20$)$

$0.80(0.67$ to 0.95$)$

0.79 (0.59 to 1.03$)$

$1.04(0.87$ to 1.24$)$

0.99 (0.65 to 1.31$)$

PL $\quad 1.02(0.87$ to 1.20$) \quad 0.98(0.73$ to 1.23$)$

represents the number of trials reporting on each outcome, with a study duration $>1$ year, or enrolling patients with mean $\mathrm{FEV}_{1}<50 \%$ of predicted value at baseline

$\mathrm{Crl}$, credible interval; $\mathrm{FEV}_{1}$, forced expiratory volume

solution delivered via Resipmat Soft Mist Inhaler. 


\begin{tabular}{llllllll}
\hline Comparison & $\begin{array}{l}\text { TIO-SMl } \\
\text { daily } \\
\text { dose }\end{array}$ & $\begin{array}{l}\text { Overall death } \\
(\mathrm{N}=42)\end{array}$ & $\begin{array}{l}\text { Favor } \\
\mathrm{OR}(95 \% \mathrm{Crl})\end{array}$ & $\begin{array}{l}\text { TlO-SMl } \\
\text { comparator }\end{array}$ & $\begin{array}{l}\text { Cardiouascular } \\
\text { death }(\mathrm{N}=31) \\
\text { OR }(95 \% \mathrm{Crl})\end{array}$ & $\begin{array}{l}\text { Favor } \\
\text { TIO-SMl }\end{array}$ & $\begin{array}{l}\text { Favor } \\
\text { comparator }\end{array}$ \\
\hline
\end{tabular}

\begin{tabular}{lrl}
\hline $\begin{array}{l}\text { Fixed effect } \\
\text { TIO-SHI us }\end{array}$ & 5 & $1.59(1.07$ to 2.38$)$ \\
TIO-HH & 10 & $2.32(1.06$ to 5.52$)$ \\
\hline LABA & 5 & $1.57(1.04$ to 2.37$)$ \\
& 10 & $2.30(1.04$ to 5.51$)$ \\
LABA-ICS & 5 & $1.84(1.22$ to 2.79$)$ \\
\hline ICS & 10 & $2.69(1.21$ to 6.42$)$ \\
& 5 & $1.42(0.94$ to 2.14$)$ \\
PL & 10 & $2.08(0.93$ to 4.95$)$ \\
& 5 & $1.46(1.01$ to 2.14$)$ \\
& 10 & $2.14(0.98$ to 5.03$)$
\end{tabular}

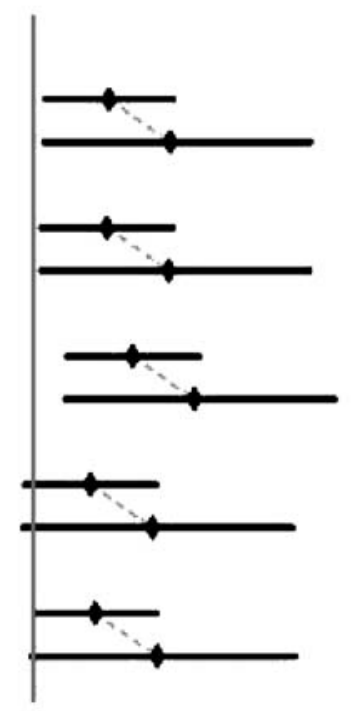

2.52 (1.25 to 5.31$)$

2.74 (0.21 to 84.71)

3.21 (1.57 to 6.91 )

$3.51(0.27$ to 112.30$)$

$2.96(1.45$ to 6.35$)$

$3.22(0.25$ to 103.10$)$

2.53 (1.24 to 5.39$)$

$2.74(0.21$ to 85.93$)$

2.18 (1.15 to 4.41$)$

$2.37(0.19$ to 74.62$)$

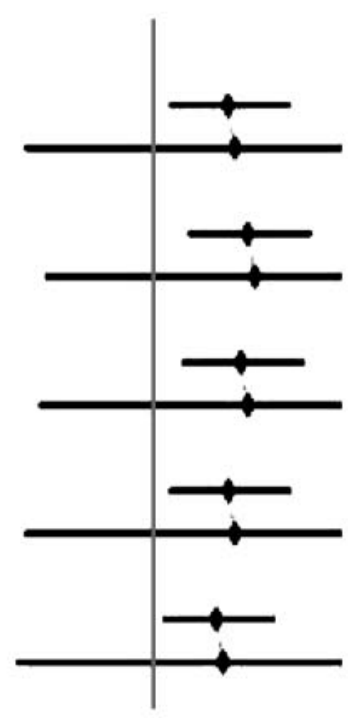

\section{Random effects}

TIO-SHI us

\begin{tabular}{lrr} 
TIO-HH & 5 & $1.59(0.98$ to 2.65$)$ \\
& 10 & $2.28(1.01$ to 5.79$)$ \\
\hline LABA & 5 & $1.54(0.94$ to 2.57$)$ \\
& 10 & $2.22(0.97$ to 5.58$)$ \\
\hline LABA-ICS & 5 & $1.86(1.12$ to 3.12$)$ \\
& 10 & $2.65(1.17$ to 6.73$)$ \\
\hline ICS & 5 & $1.48(0.92$ to 2.56$)$ \\
& 10 & $2.13(0.94$ to 5.49$)$ \\
\hline PL & 5 & $1.48(0.95$ to 2.34$)$ \\
& 10 & $2.12(0.96$ to 5.27$)$
\end{tabular}

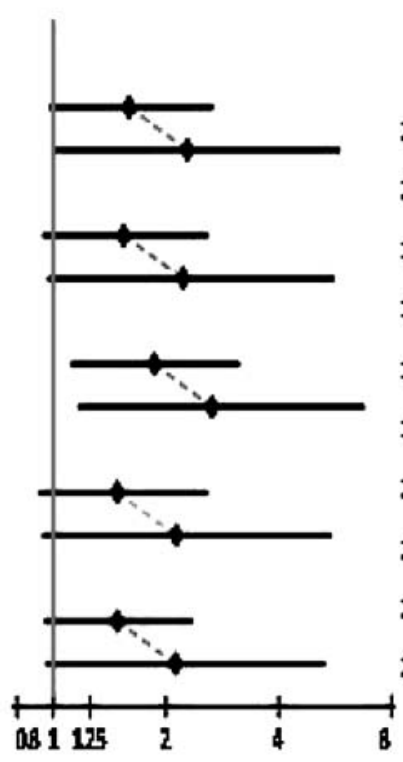

2.37 (0.78 to 7.32 )

2.38 (0.15 to 89.70 )

3.07 (0.99 to 9.46)

3.04 (0.18 to 117.50)

3.31 (1.15 to 11.46)

3.34 (0.21 to 126.90)

2.51 (0.81 to 7.95$)$

$2.52(0.15$ to 97.79$)$

2.39 (0.97 to 6.97$)$

2.42 (0.16 to 88.97)

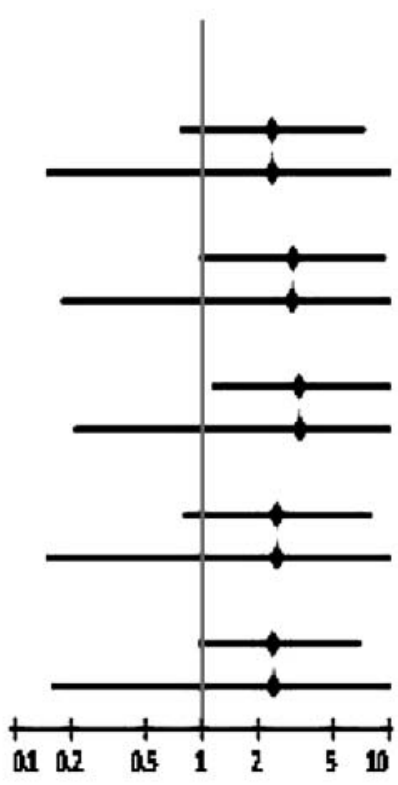

Figure 3 Stratification analysis for risk of overall death and cardiovascular death for each pairwise comparison from the MTC meta-analysis, stratified by the daily dose of tiotropium Soft Mist Inhaler. *The unit of daily dose is micrograms. Crl, credible interval; ICS, inhaled corticosteroid; LABA, long-acting $\beta 2$ agonist; MTC, mixed treatment comparison; PL, placebo; TIO-HH, tiotropium dry powder delivered via HandiHaler; TIO-SMI, tiotropium solution delivered via Resipmat Soft Mist Inhaler.

the international recognised Medical Dictionary for Regulatory Activities definition. The analysis restricted to trials with objective adjudication of cause of death also provided similar results to the main analysis. Finally, in our included trials, the withdrawal rates were variable across treatment groups, with the lowest value in the tiotropium Soft Mist Inhaler group. This may raise concerns of overestimating the relative risk of tiotropium Soft Mist Inhaler due to underestimating the mortality of placebo and other active treatments. ${ }^{35}$ However, the proportions of lost to follow-up were low across treatment groups. Moreover, vital status information was ascertained in all placebo-controlled trials of tiotropium Soft Mist Inhaler, even for patients who withdrew early. Therefore, the unfavourable bias for tiotropium Soft Mist Inhaler should be limited.

Clinical implications and conclusions

In view of the safety spectrum for each inhaled medication, our results provide substantial implications for physicians. Tiotropium Soft Mist Inhaler was associated with a 50-90\% increased risk of overall death and a twofold to threefold increased risk of cardiovascular death versus placebo and other inhaled medications. Until more evidence is available, physicians should use Tiotropium Soft Mist Inhaler with caution and the dose should not exceed the recommended daily dose. 
Alternative treatments may be considered in patients with severe COPD or with cardiac dysrhythmias.

Acknowledgements The authors would like to thank Dr Yu-Kang Tu (Association Professor, Graduate Institute of Epidemiology and Preventive Medicine, College of Public Health, National Taiwan University) for statistical consulting and Dr Kenneth R. Chapman (Director, Asthma \& Airway Centre, University Health Network, Canada) for providing additional data.

Contributors Conception and design: YHD, HHL, WYS, CHC, MSL. Analysis of the data: YHD, YCW. Interpretation of the data: YHD, HHL, WYS, CHC, MSL. Drafting of the article: YHD, HHL, WYS, CHC, MSL. Statistical expertise: HHL, WYS, CHC, MSL. Obtaining funding: MSL. All the authors have read the manuscript, revised it critically for important intellectual content, and approved the final version.

Funding This study was in part supported by the Taiwan Department of Health grant DOH098-TD-D-113-098016, which did not play any role in the study design, literature search, study selection, collection and analysis of data, interpretation of results, or drafting of the manuscript.

\section{Competing interests None.}

Provenance and peer review Not commissioned; externally peer reviewed.

\section{REFERENCES}

1 World Health Organization. The Global Burden of Disease 2004 Update. http:/l www.who.int/healthinfo/global_burden_disease/GBD_report_2004update_full.pdf (accessed 28 Jul 2011).

2 Global Initiative for Chronic Obstructive Lung Disease. Global Strategy for the Diagnosis, Management and Prevention of Chronic Obstructive Pulmonary Diseases. 2010. http://www.goldcopd.org/guidelines-publications-reviewed-2010.html (accessed 28 Jul 2011).

3 Singh S, Loke YK, Furberg CD. Inhaled anticholinergics and risk of major adverse cardiovascular events in patients with chronic obstructive pulmonary disease: a systematic review and meta-analysis. JAMA 2008;300:1439-50.

4 Cazzola M, Matera MG, Donner CF. Inhaled beta2-adrenoceptor agonists: cardiovascular safety in patients with obstructive lung disease. Drugs 2005:65:1595-610.

5 Curkendall SM, DeLuise C, Jones JK, et al. Cardiovascular disease in patients with chronic obstructive pulmonary disease, Saskatchewan Canada cardiovascular disease in COPD patients. Ann Epidemiol 2006;16:63-70.

6 Sidney S, Sorel M, Quesenberry CP Jr, et al. COPD and incident cardiovascular disease hospitalizations and mortality: Kaiser Permanente Medical Care Program. Chest 2005;128:2068-75.

7 US Food and Drug Administration. Clinical Briefing Document: NDA 21-395. Tiotropium Bromide—Pulmonary Allergy Drugs Advisory Committee Meeting. 2009. http://www.fda.gov/downloads/AdvisoryCommittees/CommitteesMeetingMaterials/ Drugs/Pulmonary-AllergyDrugsAdvisoryCommittee/UCM190463.pdf (accessed 28 Jul 2011).

8 Boehringer Ingelheim. Briefing Document: Tiotropium—Pulmonary Allergy Drugs Advisory Committee. 2009. http://www.fda.gov/downloads/AdvisoryCommittees/ CommitteesMeetingMaterials/Drugs/Pulmonary -AllergyDrugsAdvisoryCommittee/ UCM190466.pdf (accessed 28 Jul 2011).

9 US Food and Drug Administration. Follow-up to the October 2008 Updated Early Communication About An Ongoing Safety Review of Tiotropium (marketed as Spiriva ${ }^{\circledR}$ HandiHaler()). http://www.fda.gov/Drugs/DrugSafety/PostmarketDrugSafety InformationforPatientsandProviders/DrugSafetyInformationforHeathcareProfessionals/ ucm197429.htm (accessed 28 Jul 2011).

10 Voshaar T, Lapidus R, Maleki-Yazdi R, et al. A randomized study of tiotropium Respimat ${ }^{\circledR}$ Soft Mist ${ }^{\mathrm{TM}}$ inhaler vs ipratropium pMDI in COPD. Respir Med 2008;102:32-41.

11 Singh S, Loke YK, Enright PL, et al. Mortality associated with tiotropium mist inhaler in patients with chronic obstructive pulmonary disease: systematic review and meta-analysis of randomized controlled trials. BMJ 2011;342:d3215.

12 Nelson HS, Weiss ST, Bleecker ER, et al. The Salmeterol Multicenter Asthma Research Trial: a comparison of usual pharmacotherapy for asthma or usual pharmacotherapy plus salmeterol. Chest 2006;129:15-26.
13 US Food and Drug Administration. Drug Safety Communication: New Safety Requirements for Long-Acting Inhaled Asthma Medications Called Long-Acting Beta-Agonists (LABAs). http://www.fda.gov/Drugs/DrugSafety/

PostmarketDrugSafetyInformationforPatientsandProviders/UCM200776.htm (accessed 28 Jul 2011).

14 Kliber A, Lynd LD, Sin DD. The effects of long-acting bronchodilators on total mortality in patients with stable chronic obstructive pulmonary disease. Respir Res 2010;11:56.

15 Rodrigo GJ, Nannini LJ, Rodriguez-Roisin R. Safety of long-acting beta-agonists in stable COPD: a systematic review. Chest 2008;133:1079-87.

16 Nannini LJ, Cates CJ, Lasserson TJ, et al. Combined corticosteroid and long-acting beta-agonist in one inhaler versus placebo for chronic obstructive pulmonary disease. Cochrane Database Syst Rev 2007;(4):CD003794.

$17 L u$ G, Ades AE. Combination of direct and indirect evidence in mixed treatment comparisons. Stat Med 2004;23:3105-24.

18 Boehringer Ingelheim. Clinical Study Register. http://trials.boehringer-ingelheim. com/ com/Home/TrialResults/ (accessed 28 Jul 2011).

19 GlaxoSmithKline. Clinical Study Register.http://www.gsk-clinicalstudyregister.com/ (accessed 28 Jul 2011).

20 AstraZeneca. Clinical Study Register. http://www.astrazenecadlinicaltrials.com/ (accessed 28 Jul 2011).

21 Celli B, Decramer M, Leimer I, et al. Cardiovascular safety of tiotropium in patients with COPD. Chest 2010;137:20-30.

22 Higgins JPT, Green S, eds. Cochrane Handbook for Systematic Reviews of Interventions Version 5.1.0. 2011. The Cochrane Collaboration, 2011. http://www. cochrane-handbook.org (accessed 28 Jul 2011).

23 Bradburn MJ, Deeks JJ, Berlin JA, et al. Much ado about nothing: a comparison of the performance of meta-analytical methods with rare events. Stat Med 2007:26:53-77.

24 Sweeting MJ, Sutton AJ, Lambert PC. What to add to nothing? Use and avoidance of continuity corrections in meta-analysis of sparse data. Stat Med 2004:23:1351-75.

25 Bucher $\mathrm{HC}$, Guyatt $\mathrm{GH}$, Griffith $\mathrm{LE}$, et al. The results of direct and indirect treatment comparisons in meta-analysis of randomized controlled trials. J Clin Epidemiol 1997;50:683-91.

26 Rodrigo GJ, Castro-Rodriguez JA, Plaza V. Safety and efficacy of combined long-acting beta-agonists and inhaled corticosteroids vs long-acting beta-agonists monotherapy for stable COPD: a systematic review. Chest 2009;136:1029-38.

27 Nannini LJ, Cates CJ, Lasserson TJ, et al. Combined corticosteroid and long-acting beta-agonist in one inhaler versus inhaled steroids for chronic obstructive pulmonary disease. Cochrane Database Syst Rev 2007;(4):CD006826.

28 Baker WL, Baker EL, Coleman Cl. Pharmacologic treatments for chronic obstructive pulmonary disease: a mixed-treatment comparison meta-analysis. Pharmacotherapy 2009;29:891-905.

29 Van Noord JA, Cornelissen PJ, Aumann JL, et al. The efficacy of tiotropium administered via Respimat ${ }^{\circledR}$ Soft Mist ${ }^{\mathrm{TM}}$ inhaler or HandiHaler $\AA$ in COPD patients. Respir Med 2009:103:22-9.

30 Ichinose M, Fujimoto T, Fukuchi Y. Tiotropium 5 microg via Respimat $\circledast$ and 18 microg via HandiHaler®; efficacy and safety in Japanese COPD patients. Respir Med 2010;104:228-36.

31 ClinicalTrials.gov. Comparison of Tiotropium in the HandhiHaler versus the Respimat in Chronic Obstructive Pulmonary Disease. NCT01126437. http://clinicaltrials.gov/ ct2/show/study/NCT01126437 (accessed 28 Jul 2011).

32 Gershon A, Croxford R, To T, et al. Comparison of inhaled long-acting $\beta$-agonist and anticholinergic effectiveness in older patients with chronic obstructive pulmonary disease: a cohort study. Ann Intern Med 2011;154:583-92.

33 Song $\mathrm{F}$, Loke YK, Walsh T, et al. Methodological problems in the use of indirect comparisons for evaluating healthcare interventions: survey of published systematic reviews. BMJ 2009;338:b1147.

34 Song F, Xiong T, Parekh-Bhurke $S$, et al. Inconsistency between direct and indirect comparisons of competing interventions: meta-epidemiological study. BMJ 2011;343:d4909

35 Kesten S, Plautz M, Piquette CA, et al. Premature discontinuation of patients: a potential bias in COPD clinical trials. Eur Respir J 2007;30:898-906. 